\title{
Endothelium-dependent contraction of canine coronary artery is enhanced by crystalloid cardioplegic solution
}

Experiments were designed to determine whether hyperkalemic crystalloid cardioplegic solution enhances endothelium-dependent contraction of coronary arteries. Segments of canine coronary arteries ( $n=8$ in each group) were preserved in cold $\left(4^{\circ} \mathrm{C}\right)$ crystalloid cardioplegic solution (group 1) and physiologic solution (group 2) for 60 minutes. Segments of preserved and control (group 3 ) coronary arteries with or without endothelium were suspended in organ chambers to measure isometric force. Perfusate hypoxia (oxygen tension $35 \pm 5 \mathrm{~mm} \mathrm{Hg}$ ) caused endothelium-dependent contraction in the arteries of all three groups. However, vascular segments with endothelium of group 1 exhibited hypoxic contraction $(68.5 \% \pm 15.3 \%$ of the initial tension contracted by prostaglandin $\left.F_{2 \alpha} 2 \times 10^{-6} \mathrm{~mol} / \mathrm{L}, p<0.05\right)$ that was significantly greater than contraction of the group 2 and group 3 segments with endothelium $(26.6 \% \pm 5.6 \%$ and $20.6 \pm 4.4 \%)$. The hypoxic contraction in arteries of group 1 could be attenuated by $\mathbf{N}^{G}$-monomethyl-L-arginine, the blocker of endothelial cell synthesis of the nitric oxide from $L$-arginine. The action of $N^{G}$-monomethyl-Larginine could be reversed by $L$-arginine but not $D$-arginine. Thus after preservation with cardioplegic solution, augmented endothelium-dependent contraction, occurs by L-arginine-dependent pathway, would favor coronary vasospasm after cardiac operation. (J THORAC CARDIOVASC SURG 1995; 109:99-105)

Pyng Jing Lin, MD, Chau-Hsiung Chang, MD, Pei-Chin Yao, BS, Hui-Ping Liu, MD, Hung-Chang Hsieh, MD, and Kuei-Ton Tsai, MD, Taipei, Taiwan, Republic of China

$\mathrm{O}$ ver the past decade, refinement of techniques for myocardial protection and extracorporeal circulation have lowered the risk of cardiac surgery. The effect of global ischemia and reperfusion on coronary vascular reactivity and endothelial cell function

From the Division of Thoracic and Cardiovascular Surgery, Chang Gung Memorial Hospital, Chang Gung Medical College, Taipei, Taiwan, Republic of China.

Supported in part by grant NSC 83-0412 B-182-018 from the National Science Council, Executive Yuan, Taiwan, Republic of China, and by the grant 355 from the Chang Gung Memorial Hospital, Chang Gung Medical College, Taipei, Taiwan, Republic of China.

Received for publication Jan. 6, 1994.

Accepted for publication May 30, 1994.

Address for reprints: Pyng Jing Lin, MD, Division of Thoracic and Cardiovascular Surgery, Chang Gung Memorial Hospital, 199, Tun-Hwa North Rd., Taipei, Taiwan, Republic of China.

Copyright (C) 1995 by Mosby-Year Book, Inc.

$0022-5223 / 95 \$ 3.00+0 \quad \mathbf{1 2 / 1 / 5 7 9 9 0}$ has been investigated recently., ${ }^{1,2}$ However, little is known about the effects of cardioplegic solution on the coronary endothelium.

Several recent laboratory experiments have suggested that hyperkalemic cardioplegic solutions impair endothelial cell production of endotheliumderived relaxing factor. ${ }^{3,4}$ However, in these studies the effect of infusion (i.e., shear stress and barotrauma) could not be separated from the effect of cardioplegic solution itself. Indeed, it has been reported recently that crystalloid cardioplegic solution does not alter endothelium-dependent relaxation of the epicardial coronary arteries. ${ }^{5}$ However, little is known about the effects of hyperkalemic cardioplegic solutions, frequently used for myocardial protection during cardiac surgery, on the endothelium-dependent contraction of the coronary endothelium. In this study, using a protocol designed to eliminate the variables of infusion pressure and shear stress, we evaluated the effect of cardioplegic 


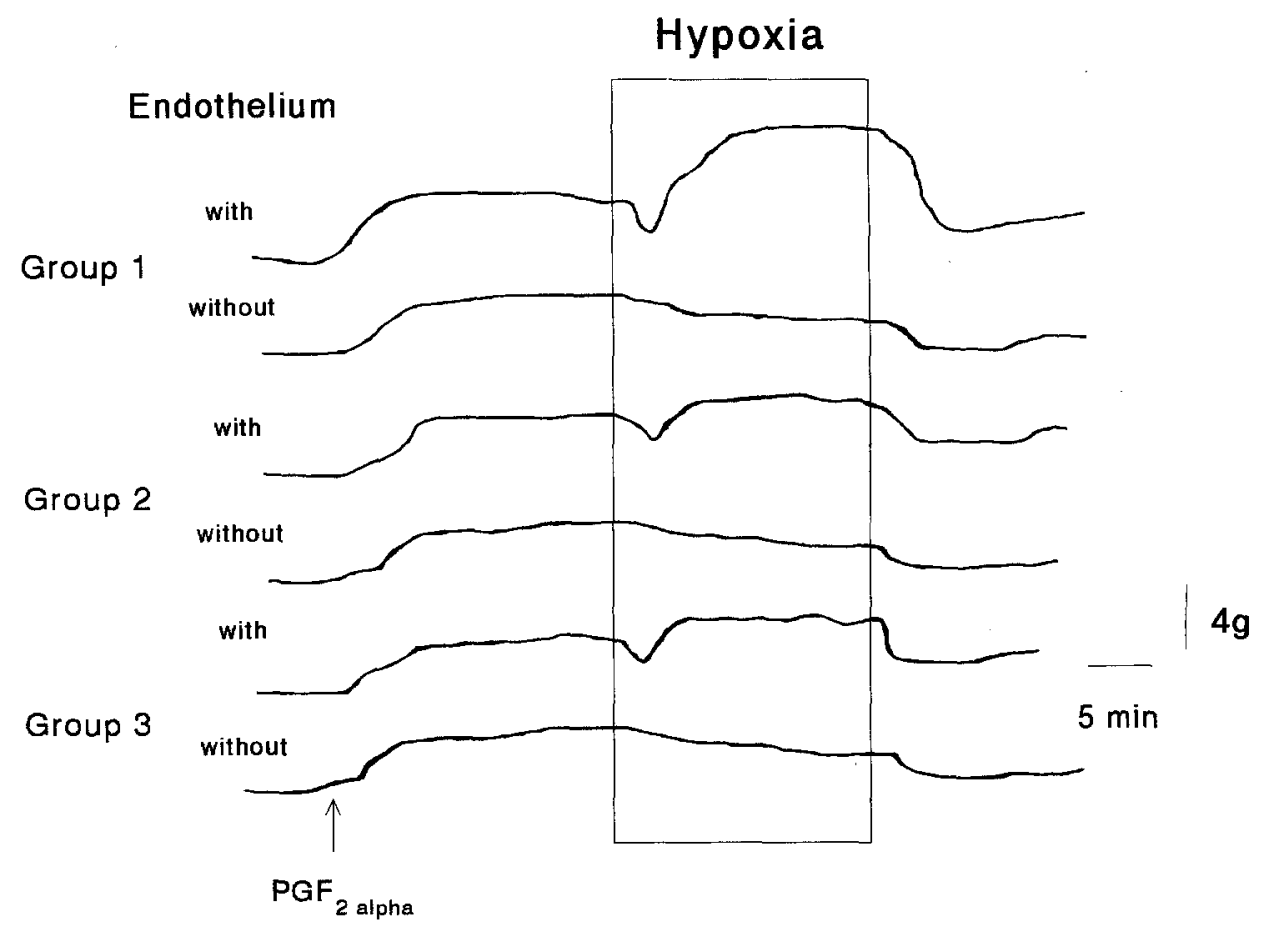

Fig. 1. Isometric tension recordings of the effect of cardioplegic solution on endothelium-dependent responses to hypoxia. Canine coronary arterial segments were preserved with crystalloid cardioplegic solution (group 1) and physiologic solution (group 2) at $4^{\circ} \mathrm{C}$ for 60 minutes. The preserved (group 1 to 2 ) and control (group 3 ) coronary segments were then suspended in an organ chamber gassed with $95 \%$ oxygen and $5 \%$ carbon dioxide $\left(\mathrm{Po}_{2} 405 \pm 15 \mathrm{~mm} \mathrm{Hg}\right)$ and contracted with prostaglandin $\mathrm{F}_{2 \alpha}\left(2 \times 10^{-6}\right.$ $\mathrm{mol} / \mathrm{L}$ ). When the contractile response to prostaglandin $\mathrm{F}_{2 \alpha}$ was stable, hypoxia was induced by changing to a $95 \%$ nitrogen $/ 5 \%$ carbon dioxide $\left(\mathrm{Po}_{2} 35 \pm 5 \mathrm{~mm} \mathrm{Hg}\right)$ gas mix. After 20 minutes, oxygenation was reintroduced.

solutions on endothelium-dependent contraction of coronary endothelial cell function in vitro.

\section{Methods and material}

\section{Methods}

Animal preparation. Twenty-four healthy mongrel dogs $(15$ to $20 \mathrm{~kg}$ ) of either sex were anesthetized with sodium pentobarbital $(30 \mathrm{mg} / \mathrm{kg}$ intravenous injection), intubated with a cuffed endotracheal tube, and their lungs ventilated with a respirator. A left lateral thoracotomy was performed, and the pericardium was opened and sutured to the chest wall to create a pericardial cradle. The heart was removed and quickly placed in cold, oxygenated solution of the following millimolar concentration: $\mathrm{NaCl}, 118.3$; $\mathrm{KCl} 4.7 ; \mathrm{MgSO}_{4} 1.2 ; \mathrm{KH}_{2} \mathrm{PO}_{4}, 1.2 ; \mathrm{CaCl}_{2}, 2.5 ; \mathrm{NaHCO}_{3}$, 25.0; and glucose, 11.1 (physiologic solution). ${ }^{6-8}$ All animals received human care in compliance with the "Guide for the Care and Use of Laboratory Animals" published by the National Institutes of Health (NIH publication No. 85-23, revised 1985).

In vitro experiments

ISOLATION OF BLOOD VESSELS. The coronary arteries were prepared as segments ( $4 \mathrm{~mm}$ in length) from the left circumflex coronary artery or left anterior descending artery. During dissection, care was taken to remove as much of the surrounding tissues as possible and to avoid stretching and rubbing the intimal surface against foreign material or the opposite wall of the vessel. To remove the endothelium, the vascular segments were placed in salinewetted paper towels. The tips of a pair of watchmaker's forceps were inserted into the lumen and the endothelial layer was removed by gently rolling the preparations back and forth over the paper for 15 seconds. ${ }^{6,7}$ Earlier studies have shown that this procedure successfully removes the endothelial cells in canine arteries and veins, while preserving the ability of the vascular smooth muscle to contract. ${ }^{6-10}$

Preservation of BloOd Vessels. The coronary arterial segments (from eight dogs in each group) with or without endothelium were randomly preserved in the following cold solutions $\left(4^{\circ} \mathrm{C}\right)$ for 60 minutes: group 1 -crystalloid cardioplegic solution (Plegisol, Abbott Laboratories, North Chicago, Ill.) with the following electrolyte composition (in milliequivalents per liter): $\mathrm{Ca}, 2.4 ; \mathrm{Mg}, 32 ; \mathrm{K}, 16$; $\mathrm{Na}, 120$; and $\mathrm{Cl}$, 160; group 2-physiologic solution with the following millimolar concentration: $\mathrm{NaCl}, 118.3 ; \mathrm{KCl}$ 4.7; $\mathrm{MgSO}_{4}, 1.2 ; \mathrm{KH}_{2} \mathrm{PO}_{4}, 1.2 ; \mathrm{CaCl}_{2}, 2.5 ; \mathrm{NaHCO}_{3}, 25.0$; and glucose, 11.1..$^{6-8}$ In group 3 (control group), however, vascular segments were placed into the organ chambers 
filled with physiologic solution $\left(37^{\circ} \mathrm{C}\right)$ immediately after harvest without preservation.

ORGAN CHAMBER EXPERIMENTS. Segments of preserved and control coronary arteries (group 1 to group 3 ) with or without endothelium were suspended in organ chambers $(25 \mathrm{ml})$ containing physiologic solution $\left(37^{\circ} \mathrm{C}\right.$, aerated with $95 \%$ oxygen and $5 \%$ carbon dioxide, oxygen tension $\left.\left[\mathrm{PO}_{2}\right] 405 \pm 15 \mathrm{~mm} \mathrm{Hg}, \mathrm{pH} 7.4\right)$. Isometric tension was recorded with strain-gauge force transducers. The blood vessels prepared as segments were suspended between two stainless steel wire stirrups passing through the lumen. The tissues were placed at the optimal point of their length-tension relationship, as determined by the response to a standard concentration of potassium ions ( 20 $\mathrm{mmol} / \mathrm{L}){ }^{6,7}$ After this procedure, the preparations were allowed to equilibrate of their optimal length for 45 minutes before the experiments.

DRUGS. The drugs, acetylcholine chloride, potassium chloride, adenosine diphosphate, D-arginine, L-arginine, $( \pm)$ isoproterenol, prostaglandin $F_{2 \alpha}$, and sodium nitroprusside, were obtained from Sigma Chemical Co., St. Louis, Missouri. $\mathrm{N}^{\mathrm{G}}$-monoethyl-L-arginine (L-NMMA) was acquired from Calbiochem Corp., San Diego, California. All drugs were prepared with distilled water. The concentrations are expressed as final molar concentration in the organ chambers.

Commercial crystalloid cardioplegic solution was prepared before each experiment by the addition of $24 \mathrm{mEq}$ of sodium bicarbonate to $1000 \mathrm{ml}$ of Plegisol solution (Abbott Laboratories). Solutions were kept at $4^{\circ} \mathrm{C}$ until used.

CALCULATIONS AND STATISTICAL ANALYSIS. The data were expressed as means \pm standard error of the mean. In all experiments, $n$ refers to the number of animals from which blood vessels were taken. Although not always mentioned in the protocol, the role of the endothelium in the observed phenomena was determined systematically by comparing blood vessels (segments) with or without endothelium to avoid repetition. Wherever possible, experiments were conducted in parallel on tissues from the same animal, to account for time-dependent changes in responsiveness of tissues. The responses gained from segments contracted with prostaglandin $F_{2 \alpha}$ were expressed as percent changes from the contracted levels. With regard to relaxations, the negative logarithm of the effective concentration (moles per liter) of agonist that caused $50 \%$ inhibition of the contraction (i.e., the median effective dose, $\mathrm{EC}_{50}$ ) to prostaglandin $\mathrm{F}_{2 \alpha}$ was calculated for concentration-response curves. For contractions, the maximal response (in grams of tension) and $\mathrm{EC}_{50}$ concentration of agonist inducing the half-maximal contraction were determined. The means of the values were presented. Statistical evaluation of data between groups was performed by analysis of variance, and Student's $t$ test was used when analysis of variance showed significance. Statistical significance was set at a probability value of less than 0.05 .

Protocol. Segments of coronary artery with or without endothelium from the same animal were placed in our eight-bath organ chamber system, studied, and compared. The following procedures were performed:

1. Segments were preserved in the cold solution $\left(4^{\circ} \mathrm{C}\right)$ for 60 minutes, except vascular segments of group 3 .
Table I. Endothelium-independent vascular smooth muscle contractions of segments of canine coronary arteries

\begin{tabular}{|c|c|c|c|}
\hline & Group 1 & Group 2 & Group 3 \\
\hline & \multicolumn{3}{|c|}{$E C_{50} *$} \\
\hline \multicolumn{4}{|l|}{ Potassium } \\
\hline With endothelium & $10.3 \pm 0.5$ & $10.0 \pm 0.6$ & $9.5 \pm 0.4$ \\
\hline Without endothelium & $9.7 \pm 0.4$ & $9.4 \pm 0.7$ & $9.3 \pm 0.5$ \\
\hline \multicolumn{4}{|l|}{ Prostaglandin $F_{2 \alpha}$} \\
\hline With endothelium & $5.7 \pm 0.5$ & $5.4 \pm 0.2$ & $5.3 \pm 0.5$ \\
\hline \multirow[t]{2}{*}{ Without endothelium } & $6.0 \pm 0.4$ & $6.3 \pm 0.5$ & $5.9 \pm 0.5$ \\
\hline & \multicolumn{3}{|c|}{ Maximal contraction $(\mathrm{gm}) \dagger$} \\
\hline \multicolumn{4}{|l|}{ Potassium } \\
\hline With endothelium & \multicolumn{3}{|c|}{$10.72 \pm 0.8211 .05 \pm 0.9110 .78 \pm 1.27$} \\
\hline Without endothelium & \multicolumn{3}{|c|}{$11.23 \pm 1.4510 .89 \pm 1.3711 .52 \pm 0.81$} \\
\hline \multicolumn{4}{|c|}{ Prostaglandin $\mathrm{F}_{2 \alpha}$} \\
\hline With endothelium & \multicolumn{3}{|c|}{$10.25 \pm 1.4510 .50 \pm 1.3710 .53 \pm 0.97$} \\
\hline Without endothelium & $11.27 \pm 1.33$ & $10.56 \pm 1.22$ & $11.41 \pm 1.51$ \\
\hline
\end{tabular}

Values were given as means \pm standard error of the mean. Sample size for all groups was 8 . There was no significant difference between groups.

${ }^{*}$ Concentration of agonist inducing the half-maximal contraction expressed as $\mathrm{mmol} / \mathrm{L}$ for potassium-induced contractions and as $-\log \mathrm{mol} / \mathrm{L}$ for prostaglandin $F_{2 \alpha}$-induced contractions.

$\uparrow$ Values were given as means \pm standard error of the mean of the maximal contraction induced by agonists.

2. Segments were suspended in organ chambers $(25 \mathrm{ml})$ containing physiologic solution $\left(37^{\circ} \mathrm{C}\right)$.

3. Studies of endothelium-dependent relaxation were done. Segments (with and without endothelium) of coronary artery from animals were suspended in organ chambers. They were contracted with prostaglandin $F_{2 \alpha}(2 \times$ $\left.10^{-6} \mathrm{~mol} / \mathrm{L}\right)$ and then exposed to increasing concentrations $\left(10^{-9}\right.$ to $\left.10^{-4} \mathrm{~mol} / \mathrm{L}\right)$ of acetylcholine and adenosine diphosphate.

4. Studies of endothelium-independent relaxation were done. To test the ability of the smooth muscle to relax, we obtained concentration-response curves to sodium nitroprusside (mediated by cyclic guanosine monophosphate, $10^{-9}$ to $10^{-4} \mathrm{~mol} / \mathrm{L}$ ) and isoproterenol (mediated by cyclic adenosine monophosphate, $10-9$ to $10^{-4} \mathrm{~mol} / \mathrm{L}$ ) after they were contracted with prostaglandin $\mathrm{F}_{2 \alpha}\left(2 \times 10^{-6}\right.$ $\mathrm{mol} / \mathrm{L}$ ).

5. Studies of endothelium-dependent contraction to hypoxia were done. The vascular segments with or without endothelium were contracted with prostaglandin $F_{2 \alpha}(2 \times$ $10^{-6} \mathrm{~mol} / \mathrm{L}$ ) (initial tension) in an organ chamber gassed with $95 \%$ oxygen and $5 \%$ carbon dioxide $\left(\mathrm{PO}_{2} 405 \pm 15\right.$ $\mathrm{mm} \mathrm{Hg}$ ). When the contractile response to prostaglandin $F_{2 \alpha}$ was stable, hypoxia was induced by aerating the organ bath with a mixture of $95 \%$ nitrogen and $5 \%$ carbon dioxide ( $\mathrm{pH} 7.4, \mathrm{Po}_{2} 35 \pm 5 \mathrm{~mm} \mathrm{Hg}, 20$ minutes). ${ }^{2,6}$ After 20 minutes, oxygenation was reintroduced. Vascular segments were exposed to only one hypoxic period.

6. Studies of endothelium-independent contraction were done. To test the ability of the smooth muscle to contract, we obtained concentration-response curves to potassium ions ( 5 to $50 \mathrm{mmol} / \mathrm{L}$, voltage-dependent) and prostaglandin $F_{2 \alpha}$ $\left(10^{-9}\right.$ to $10^{-4} \mathrm{~mol} / \mathrm{L}$, receptor-dependent $)$. 


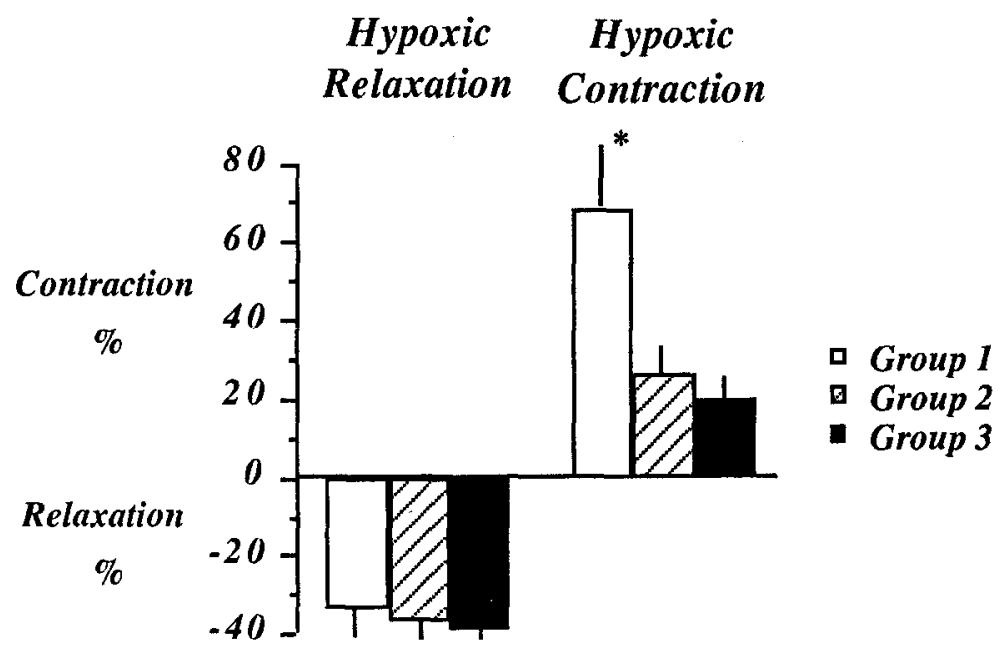

Fig. 2. Effect of hypoxia ( $95 \%$ nitrogen $/ 5 \%$ carbon dioxide) on tension in contracted (by prostaglandin $F_{2 \alpha}$ $2 \times 10^{-6} \mathrm{~mol} / \mathrm{L}$ ) canine coronary arterial segments with endothelium of all three groups. Data are shown as means \pm standard error of the mean and are expressed as percent change from the initial contraction to prostaglandin $\mathrm{F}_{2 \alpha}$ (zero on $y$ axis). "Significant difference from segments with endothelium of other groups.

\section{Results}

Endothelium-dependent contraction to hypoxia. Preserved (group 1 and group 2) and control (group 3) coronary arterial segments with and without endothelium had comparable contractile responses to prostaglandin $F_{2 \alpha}$ (initial tension, Fig. 1 and Table I). On exposure to hypoxia, contracted preserved and control coronary segments with endothelium exhibited comparable relaxations (hypoxic relaxation) (groups 1 to $3,34 \% \pm 5 \%, 37 \% \pm 4 \%$, and $39 \% \pm 4 \%$ of initial tension, respectively, $p>0.05$; Fig. 2). In vascular segments with endothelium of all three groups, hypoxia induced contractions (hypoxic contraction) that were significantly greater than in segments without endothelium (Fig. 1). However, coronary arterial segments of group 1 with endothelium exhibited augmented contractions to hypoxia $(68.5 \% \pm 15.3 \%$ greater contraction than initial tension), which were significantly greater than those in segments of groups 2 and 3 with endothelium (26.6\% $\pm 5.6 \%$ and $20.6 \% \pm 4.4 \%$ greater contraction than initial tension, respectively, $p<0.02$ ) (Figs. 1 and 2). This endothelium-dependent hypoxic contraction could be attenuated by pretreatment with L-NMMA $\left(10^{-5} \mathrm{~mol} / \mathrm{L}\right.$, a nitric oxide synthase inhibitor) in segments of all three groups with endothelium (Fig. 3). The effect of L-NMMA could be blocked with $\mathrm{L}$-arginine (precursor of nitric oxide, $10^{-4} \mathrm{~mol} / \mathrm{L}$ ) but not by $\mathrm{D}$-arginine (analog of L-arginine, $10^{-4} \mathrm{~mol} / \mathrm{L}$ ) (Fig. 3). L-NMMA, L-arginine, and $\mathrm{D}$-arginine had no effects on the hypoxic responses of preserved and control segments without endothelium. L-NMMA also did not change the baseline tension (before contraction with prostaglandin $\mathrm{F}_{2 \alpha}$ ) of the preserved and control segments with or without endothelium.

Endothelium-dependent relaxation. Increasing concentrations $\left(10^{-9}\right.$ to $\left.10^{-4} \mathrm{~mol} / \mathrm{L}\right)$ of acetylcholine and adenosine diphosphate induced comparable concentration-dependent relaxation in coronary artery segments with endothelium in all groups. They produced no significant change in tension in coronary artery segments without endothelium. In all groups, the maximal relaxation or sensitivity $\left(\mathrm{EC}_{50}\right)$ to agonist-induced relaxation in coronary artery segments with endothelium did not change (Table II).

Endothelium-independent relaxation. Increasing concentrations $\left(10^{-9}\right.$ to $\left.10^{-4} \mathrm{~mol} / \mathrm{L}\right)$ of isoproterenol and sodium nitroprusside induced comparable concentration-dependent relaxation in coronary artery segments without endothelium in all groups. In all groups, the maximal relaxation induced by isoproterenol or sodium nitroprusside was not altered in coronary artery segments without endothelium, nor did this induction change the sensitivity to relaxation of the vascular smooth muscle (see Table II).

Endothelium-independent contraction. Increasing concentration of potassium ions $(5$ to $50 \mathrm{mmol} / \mathrm{L}$ ) and prostaglandin $\mathrm{F}_{2 \alpha}\left(10^{-9}\right.$ to $\left.10^{-4} \mathrm{~mol} / \mathrm{L}\right)$ induced comparable, concentration-dependent contraction 


\section{$\begin{array}{lll}\text { Group 1 } & \text { Group 2 } & \text { Group } 3\end{array}$}

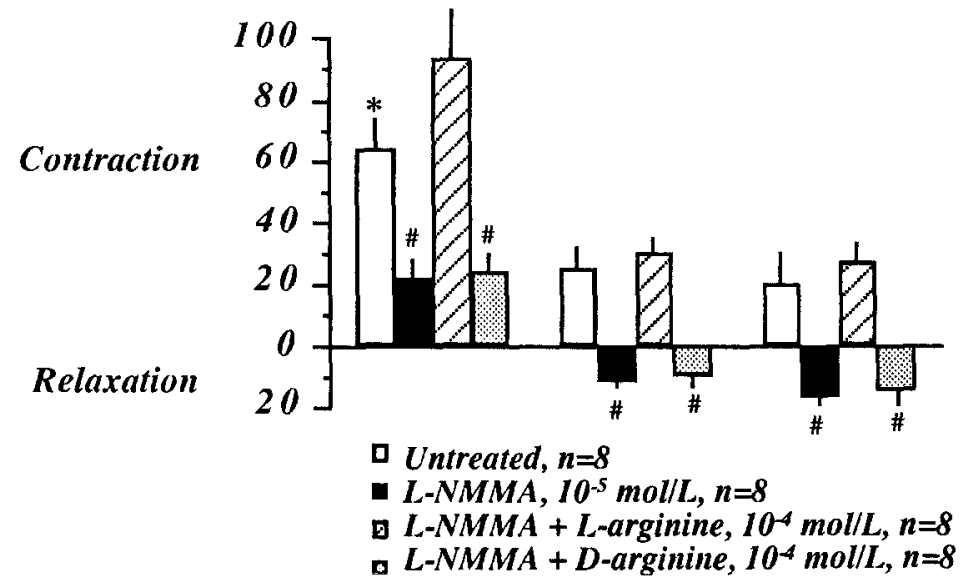

Fig. 3. Effect of hypoxia and drugs on tension in contracted (by prostaglandin $\mathrm{F}_{2 \alpha} 2 \times 10^{-6} \mathrm{~mol} / \mathrm{L}$ ) canine coronary arterial segments with endothelium of all three groups. Data are shown as means \pm standard error of the mean and expressed as percent of the initial contraction to prostaglandin $\mathrm{F}_{2 \alpha^{*}}{ }^{*}$ Significant difference from control untreated segments (group 3) with endothelium $(p<0.02)$. ${ }^{\text {\# Significant difference }}$ from untreated segments with endothelium in the same group $(p<0.05)$. L-NMMA, $\mathrm{N}^{\mathrm{G}}$-monomethyl-Larginine.

of arterial segments with or without endothelium in all groups. The maximal response or the sensitivity to these agonists did not have any significant changes in any of the groups (see Table I).

\section{Discussion}

The major finding of this study is that hypoxia induced augmented endothelium-dependent contraction in canine coronary endothelium preserved with crystalloid cardioplegic solution. L-NMMA (a nitric oxide synthase inhibitor) attenuated this endothelium-dependent hypoxic contraction, indicating that this hypoxic contraction was induced by an L-arginine-dependent pathway. We also found that hyperkalemic crystalloid cardioplegic solution did not alter endothelium-dependent relaxation function of epicardial coronary arteries. In addition, smooth muscle contraction in response to potassium ions (voltage-dependent) or prostaglandin $\mathrm{F}_{2 \alpha}$ (receptor-dependent) and relaxation in response to isoproterenol (cyclic adenosine monophosphatemediated) or sodium nitroprusside (cyclic guanosine monophosphate-mediated) was well preserved after exposure to crystalloid cardioplegic solution.

The coronary endothelium releases endotheliumderived relaxing factor(s), which relaxes the underlying vascular smooth muscle. Endothelium-derived relaxing factor regulates arterial tone and thus par-
Table II. Endothelium-dependent and-independent relaxation of segments of canine coronary arteries

\begin{tabular}{|c|c|c|c|}
\hline & Group 1 & Group 2 & Group 3 \\
\hline & \multicolumn{3}{|c|}{$E C_{50}(-\log \mathrm{mol} / \mathrm{L}) *$} \\
\hline \multicolumn{4}{|l|}{ With endothelium } \\
\hline Acetylcholine & $6.85 \pm 0.31$ & $7.10 \pm 0.11$ & $6.92 \pm 0.24$ \\
\hline Adenosine diphosphate & $6.65 \pm 0.22$ & $6.52 \pm 0.14$ & $6.49 \pm 0.08$ \\
\hline \multicolumn{4}{|c|}{ Without endothelium } \\
\hline Isoproterenol & $7.71 \pm 0.05$ & $7.63 \pm 0.10$ & $7.52 \pm 0.15$ \\
\hline Sodium nitroprusside & $7.95 \pm 0.08$ & $7.91 \pm 0.12$ & $7.87 \pm 0.09$ \\
\hline & \multicolumn{3}{|c|}{ Maximal relaxation $(\%) \dagger$} \\
\hline \multicolumn{4}{|l|}{ With endothelium } \\
\hline Acetylcholine & $95.5 \pm 2.1$ & $96.0 \pm 1.1$ & $96.5 \pm 2.5$ \\
\hline Adenosine diphosphate & $94.5 \pm 2.7$ & $92.7 \pm 4.1$ & $93.5 \pm 3.5$ \\
\hline \multicolumn{4}{|c|}{ Without endothelium } \\
\hline Isoproterenol & 100 & 100 & 100 \\
\hline Sodium nitroprusside & 100 & 100 & 100 \\
\hline
\end{tabular}

Sample size for all groups was 8 . There was no significant difference between groups.

*Values were given as means \pm standard error of the mean of the negative logarithms of the concentration ( $\mathrm{mol} / \mathrm{L}$ ) of agonists causing $50 \%$ inhibition of contractions (i.e., the median effective dose) induced by prostaglandin $\mathrm{F}_{2 \alpha}\left(2 \times 10^{-6} \mathrm{~mol} / \mathrm{L}\right)$.

$\dagger$ Values were given as means \pm standard error of the mean of the maximal inhibition of contraction induced by prostaglandin $\mathrm{F}_{2 \alpha}\left(2 \times 10^{-6} \mathrm{~mol} / \mathrm{L}\right)$ with the agonists $\left(10^{-4} \mathrm{~mol} / \mathrm{L}\right)$.

ticipates in control of coronary blood flow. In the normal coronary artery, release of endotheliumderived relaxing factor is stimulated by aggregating platelets, shear stress, and other vasoactive agents. 
The major endothelium-derived relaxing factor is nitric oxide, which serves as the coronary arteries' own physiologic nitrovasodilator. ${ }^{11}$ In addition to relaxing vascular smooth muscle, endothelium-derived relaxing factor also prevents platelet adhe$\operatorname{sion}^{12}$ and aggregation ${ }^{13}$ and promotes platelet disaggregation in normal blood vessels. ${ }^{14}$ Thus endothelium-derived relaxing factor induces vasodilation directly and inhibits platelet-mediated vasospasm and thrombus formation.

$\mathrm{We}^{1}$ have previously demonstrated that endothelium-dependent relaxation was impaired after cardiac global ischemia and reperfusion. Impaired release of relaxing factor would promote platelet adhesion and aggregation as well as platelet-induced construction of the underlying smooth muscle. These events could lead to vasospasm and thrombosis. ${ }^{9}$ Previous reports have suggested that hyperkalemic cardioplegic solutions impair endothelial cell production of endothelium-derived relaxing factor. $^{3,4}$ However, Evora, Pearson, and Schaff ${ }^{5}$ reported recently that crystalloid cardioplegic solution does not alter endothelium-dependent relaxation of the epicardial coronary arteries. Our data also clearly showed that crystalloid cardioplegic solution does not alter endothelium-dependent relaxation to acetylcholine and adenosine diphosphate of epicardial coronary arteries. Crystalloid cardioplegic solution does not alter endothelium-independent smooth muscle relaxation to isoproterenol and sodium nitroprusside.

The coronary endothelium can also produce contracting factor. When exposed to hypoxia or regenerated after mechanical injury, the endothelium exhibits augmented contraction, ${ }^{6-7,10,15-18} \mathrm{We}^{6,8,17,18}$ have described endothelium-dependent contractions caused by hypoxia in the human and canine internal mammary arteries. $\mathrm{We}^{2}$ also found that the endothelium-dependent contraction was enhanced after coronary ischemia and reperfusion. Augmented endothelium-dependent contraction after coronary ischemia and reperfusion ${ }^{2}$ appear to be important factors in coronary vasospasm after ischemia and reperfusion of coronary arteries.

Even before the importance of endothelium-dependent responses was recognized, investigators demonstrated that hypoxia augments contraction to several vasoactive agents in isolated blood vessels. ${ }^{19-21}$ Vanhoutte and coworkers ${ }^{10,22,23}$ subsequently determined that in canine coronary and femoral arteries, hypoxic augmentation of contraction was due to a diffusible factor released by the endothelium, which they termed endothelium-derived contracting factor. Endothelium-dependent contraction to hypoxia in these canine blood vessels is not modified by inhibitors of cyclooxygenase, lipoxygenase, phospholipase $\mathrm{A}_{2}$, serotonergic or histaminergic blockers, the radical generators quinacrine or phenidone, or by methylene blue. ${ }^{10}$ In addition, these finding of the rapid onset and reversal of the contraction and the inability to bioassay the contracting factor rule out the vasoconstrictor peptide endothelin as the mediator of this response. ${ }^{23}$

Endothelium-dependent contraction to hypoxia in the canine coronary artery and internal mammary artery can be blocked by L-NMMA, ${ }^{2,6,8}$ the competitive inhibitor of nitric oxide synthesis from $\mathrm{L}$ arginine. ${ }^{24}$ Nitric oxide has been identified as the active component of endothelium-derived relaxing factor. ${ }^{11}$ In this study, we found that hyperkalemic cardioplegic solution could induce augmented endothelium-dependent contraction in canine coronary endothelium on exposure to hypoxia. This endothelium-dependent hypoxic contraction could be attenuated by L-NMMA, which indicates that this hypoxic contraction was induced by an L-arginine-dependent pathway. Such a mechanism would be consistent with the finding of enhanced endothelium-dependent contraction to hypoxia in the human internal mammary artery ${ }^{6,8}$ and augmented production of endothelium-derived contracting factor following canine coronary reperfusion after global ischemia. ${ }^{2}$

Coronary arteries may be exposed to hypoxia in the perioperative period after cardiac operations. Low cardiac output, intrapulmonary shunting of blood, and alveolar hypoventilation are recognized causes of perioperative hypoxemia. However, coronary arteries may also be exposed to local hypoxia or ischemia primarily to occluded vein grafts or vasospastic internal mammary arterial grafts ${ }^{6,8}$ in cases of coronary artery bypass grafting or secondarily to impaired release of endothelium-derived relaxing factor from coronary endothelium after global ischemia and reperfusion. ${ }^{1}$ It has been shown that endothelium-dependent relaxation was impaired after cardiac local or global ischemia and reperfusion. ${ }^{1,25,26}$ Because endothelium-derived relaxing factor relaxes vascular smooth muscle and inhibits platelet adhesion and aggregation in the blood vessel, such an impairment could put the graft at risk for ischemic events such as vasospasm and thrombosis. The present study suggests that if an ischemic event were to occur after a cardiac operation, tissue 
hypoxia would increase production of endotheliumderived contracting factor by the coronary endothelium that was preserved by cardioplegic solution and injured by ischemia and reperfusion during cardiac surgery, thereby inducing or exacerbating coronary vasospasm. Indeed, such a sequence of events could lead to cardiovascular collapse at a time when the heart is exquisitely sensitive to ischemia because of preexisting myocardial disease or intraoperative injury.

\section{REFERENCES}

1. Pearson PJ, Lin PJ, Schaff HV. Global myocardial ischemia and reperfusion impair endothelium-dependent relaxations to aggregating platelets in the canine coronary artery: a possible cause of vasospasm after cardiopulmonary bypass. J THORAC CARDIOvASC SURG 1992;103:1147-54.

2. Pearson PJ, Lin PJ, Schaff HV. Production of endothelium-derived contracting factor is enhanced following coronary reperfusion. Ann Thorac Surg 1991; 51:788-93.

3. Saldanha C, Hearse DJ. Coronary vascular responsiveness to 5-hydroxytryptamine before and after infusion of hyperkalemic crystalloid cardioplegic solution in the rat heart: possible evidence of endothelial damage. J Thorac Cardiovasc SuRg 1989;98:783-7.

4. Mankad PS, Chester AH, Yacoub MH. Role of potassium concentration in cardioplegic solutions in mediating endothelial damage. Ann Thorac Surg 1991;51:89-93.

5. Evora PRB, Pearson PJ, Schaff HV. Crystalloid cardioplegia and hypothermia do not impair endothelium-dependent relaxation or damage vascular smooth muscle of epicardial coronary arteries. J THORAC CARDIOVASC SURG 1992;104:1365-74.

6. Lin PJ, Pearson PJ, Schaff HV. Endothelium-dependent contraction and relaxation of the human and canine internal mammary artery: studies on bypass graft vasospasm. Surgery 1991;110:127-35.

7. Lin PJ, Pearson PJ, Cartier HV, Schaff HV. Superoxide anion mediates the endothelium-dependent contractions to serotonin by regenerated endothelium. J Thorac Cardiovasc Surg 1991;102:378-85.

8. Pearson PJ, Lin PJ, Evora PRB, Schaff HV. Endothelium-dependent response of human internal mammary artery to hypoxia. Am J Physiol 1993;264:H37680.

9. Vanhoutte PM, Shimokawa H. Endothelium-derived relaxing factor and coronary vasospasm. Circulation 1989;80:1-9.

10. Rubanyi GM, Vanhoutte PM. Hypoxia releases a vasoconstrictor substance from the canine vascular endothelium. J Physiol 1985;364:45-56.

11. Palmer RMJ, Ferrige AG, Moncada S. Nitric oxide release accounts for the biological activity of endothelium-derived relaxing factor. Nature 1987;327:524-6.

12. Sneddon JM, Vane JR. Endothelium-derived relaxing factor reduces platelet adhesion to bovine endothelial cells. Proc Natl Acad Sci U S A 1988;85:2800-4.

13. Azuma H, Ishikawa M, Sekizaki S. Endotheliumdependent inhibition of platelet aggregation. $\mathrm{Br} \mathrm{J}$ Pharmacol 1986;88:411-5.

14. Radomski MW, Palmer RMJ, Moncada S. Comparative pharmacology of endothelium-derived relaxing factor, nitric oxide and prostacyclin in platelets. $\mathrm{Br} \mathrm{J}$ Pharmacol 1987;92:181-7.

15. Iqbal A, Vanhoutte PM. Flunarizine inhibits endothelium-dependent hypoxic facilitation in canine coronary arteries through an action on vascular smooth muscle. Br J Pharmacol 1988;95:789-94.

16. Cartier R, Pearson PJ, Lin PJ, Schaff HV. Time course and extent of recovery of endothelium-dependent contractions and relaxations after direct arterial injury. J Thorac Cardiovasc Surg 1991;102:371-7.

17. Lin PJ, Pearson PJ, Schaff HV. Hypoxia releases a vasoconstrictor substance from the endothelium of the human internal mammary artery. Surg Forum 1990;41:311-2.

18. Lin PJ, Pearson PJ, Schaff HV. Endothelium-dependent contraction to hypoxia in the human internal mammary artery. Circulation 1990;82(Suppl):III294.

19. DeTar R, Bohr DF. Contractile responses of isolated vascular smooth muscle during prolonged exposure to anoxia. Am J Physiol 1972;222:1269-73.

20. Vanhoutte PM. Effects of anoxia and glucose depletion on isolated veins of the dog. Am J Physiol 1976;230:1261-8.

21. De Mey JG, Vanhoutte PM, Interaction between $\mathrm{Na}^{+}, \mathrm{K}^{+}$exchanges and the direct inhibitory effect of acetylcholine on canine femoral arteries. Circ Res 1980;46:826-36.

22. De Mey JG, Vanhoutte PM. Anoxia and endothelium-dependent reactivity of the canine femoral artery. J Physiol 1983;335:65-74.

23. Vanhoutte PM, Auch-Schwelk W, Boulanger C, et al. Does endothelin-1 mediate endothelium-dependent contractions during anoxia? J Cardiovasc Pharmacol 1989;13(Suppl 5):S124-8.

24. Rees DD, Palmer RMJ, Hodson HF, Moncada S. A specific inhibitor of nitric oxide formation from Larginine attenuates endothelium-dependent relaxation. Br J Pharmacol 1989;96:418-24.

25. Pearson PJ, Schaff HV, Vanhoutte PM. Acute impairment of endothelium-dependent relaxations to aggregating platelets following reperfusion injury in canine coronary arteries. Circ Res 1990;67:385-93.

26. Pearson PJ, Schaff HV, Vanhoutte PM. Long term impairment of endothelium-dependent relaxations to aggregating platelets after reperfusion injury in canine coronary arteries. Circulation 1990;81:1921-7. 